\title{
The rsR' pattern in left surface leads in ventricular aneurysm
}

\author{
Nabil El-Sherif \\ From the Cardiology Department, Faculty of Medicine, Cairo University, Cairo, \\ Egypt, U.A.R.
}

$A$ characteristic rs $R^{\prime}$ pattern or its variants $\left(r S r^{\prime}\right.$ or $\left.r S R^{\prime}\right)$ with normal or prolonged $Q R S$ duration in left surface leads including the apex lead and the orthogonal scalar $X$ lead was described in I8 patients with coronary heart disease; in I 7 of them a ventricular aneurysm was present. Necropsy in 12 patients showed the ventricular aneurysm to be secondary to an extensive confluent scarring of the anterior and antero-lateral portions of the left ventricle. Explanation of the genesis of the electrocardiographic pattern was attempted and its clinical value was suggested.

Since recent refinements in cardiovascular surgical techniques, the clinical recognition of ventricular aneurysms has become of more than academic interest. Physical examination, fluoroscopic, kymographic, and angiocardiographic studies all help to establish ante-mortem diagnosis. The electrocardiogram, however, seems to be less helpful. It has been said that there is no single characteristic cardiographic pattern of ventricular aneurysm (Schlichter, Hellerstein, and Katz, I954; Dubnow, Burchell, and Titus, 1965). The changes present are due to myocardial infarction and usually include pathological $Q$ waves, bundle-branch block, or non-specific myocardial damage. Though early electrocardiographic patterns of ventricular aneurysm have been described (Goldberger and Schwartz, I948), they lack both rationale and specificity. Persistent ST segment elevation is commonly mentioned and has been variously explained (Moyer and Hiller, I95I; Samson and Scher, 1960; Caskey and Estes, 1964), but still these signs are non-specific. A characteristic QRS pattern in left surface leads was frequently observed in association with ventricular aneurysm in this laboratory. The present report is a clinico-pathological correlation of this pattern.

\section{Material and methods}

Eighteen patients were included in the study: 17 men and $I$ woman, ranging in age from 40-67 years. All patients were primarily selected on the basis of their electrocardiographic findings of an rsR' pattern or one of its variants ( $r \mathrm{rr}^{\prime}$ or $\mathrm{rSR}^{\prime}$ ) in one or more of the left surface leads, sometimes Received 6 November 1969. including the lead overlying the apical impulse (apex lead). Patients with the characteristic electrocardiographic pattern were included in the study either if they had clear fluoroscopic evidence of ventricular aneurysm defined on the basis of paradoxical or counterpulsatile motion of a portion of the left ventricular border (Schwedel and Gross, 1939; Schwedel, 1946); and/or when necropsy was available. All patients had a full cardiological examination with particular emphasis on the presence of ventricular aneurysm. The orthogonal electrocardiogram was recorded for every patient, using the Frank lead system (Frank, 1956), with the chest electrode placed in the fourth intercostal space as recommended for patients in the supine position (Langner et al., 1958). The Frank point $C$ was found by inspection. The three scalar orthogonal leads were recorded simultaneously, two at a time in a planar projection (El-Sherif et al., 1966). The polarity in the $\mathrm{Z}$ lead was made so that positive deflexion indicated anterior direction. All records were made at a paper speed of 25 and $100 \mathrm{~mm}$./sec., using either a four-channel Elema-Schönander Mingograph type $42 \mathrm{~B}$, or a three-channel Phillips Cardiopan. From the tracings recorded at the rapid paper speed, the angular projection of the instantaneous $Q R S$ vectors was determined at fixed time intervals of $0.01 \mathrm{sec}$. for a series of 8 vectors from the onset of the QRS complex.

Post-mortem studies were done in 12 patients. The definition of ventricular aneurysm proposed by Edwards (196I) was followed. The study included the site of myocardial scarring, the size of the aneurysmal bulging, and the state of the coronary vessels.

\section{Results}

Pertinent data concerning the clinical and post-mortem findings are included in Table $I$. 
TABLE I Clinical and post-mortem findings

\begin{tabular}{|c|c|c|c|c|c|c|c|c|c|c|c|c|}
\hline \multirow{3}{*}{$\begin{array}{l}\text { Case } \\
\text { No. }\end{array}$} & \multirow{3}{*}{$\begin{array}{l}\text { Age } \\
(y r .)\end{array}$} & \multirow[t]{3}{*}{ Sex } & \multicolumn{4}{|c|}{ Clinical findings } & \multicolumn{6}{|c|}{ Post-mortem findings } \\
\hline & & & \multirow{2}{*}{$\begin{array}{l}\text { History of } \\
\text { coronary } \\
\text { disease }\end{array}$} & \multirow{2}{*}{$\begin{array}{l}\text { Congestive } \\
\text { heart } \\
\text { failure on } \\
\text { admission }\end{array}$} & \multirow{2}{*}{$\begin{array}{l}\text { Aneurysm } \\
\text { suspected } \\
\text { clinically }\end{array}$} & \multirow{2}{*}{$\begin{array}{l}\text { Aneurysm } \\
\text { diagnosed } \\
\text { by x-ray }\end{array}$} & \multicolumn{5}{|c|}{ Site of myocardial scarring (left ventricular wall) } & \multirow{2}{*}{$\begin{array}{l}\text { Size of } \\
\text {-aneurysm } \\
(\mathrm{cm} .)\end{array}$} \\
\hline & & & & & & & $\begin{array}{l}\text { Involving } \\
\text { septum }\end{array}$ & Anterior & $\begin{array}{l}\text { Antero- } \\
\text { lateral }\end{array}$ & Apical & Posterior & \\
\hline $\mathbf{I}$ & 45 & $\mathbf{M}$ & + & + & - & - & + & - & + & - & - & $5 \times 7$ \\
\hline 2 & $5 I$ & $\mathbf{M}$ & + & + & + & + & + & + & + & - & - & $16 \times 19$ \\
\hline 3 & 47 & M & + & - & - & - & + & + & + & - & - & $9 \times 12$ \\
\hline 4 & 56 & $\mathbf{M}$ & - & + & - & - & + & + & - & + & - & $8 \times 9$ \\
\hline 5 & 62 & $\mathbf{M}$ & + & - & - & + & - & + & - & - & + & $4 \times 5$ and $3 \times 4$ \\
\hline 6 & 53 & $\mathbf{M}$ & + & + & - & - & + & + & - & + & - & $\begin{array}{l}\text { No aneurysmal } \\
\text { bulging }\end{array}$ \\
\hline 7 & 49 & $M$ & + & + & - & - & + & + & + & - & - & $7 \times 9$ \\
\hline 8 & 44 & $\mathbf{M}$ & + & + & - & + & + & + & + & - & & $6 \times 7$ \\
\hline 9 & 40 & $\mathbf{M}$ & + & - & - & - & + & + & - & + & - & $4 \times 6$ \\
\hline ro & 64 & $\mathbf{M}$ & - & + & - & - & - & + & + & - & - & $7 \times 8$ \\
\hline II & 53 & $\mathbf{M}$ & - & + & + & + & + & + & + & - & - & Iny 1 \\
\hline 12 & 48 & $\mathbf{M}$ & + & - & & - & + & & & & & \\
\hline 13 & 58 & $\mathbf{M}$ & + & - & + & + & & & & & & \\
\hline 14 & $6 I$ & $\mathbf{M}$ & + & + & + & + & & & & & & \\
\hline I5 & 47 & $\mathbf{M}$ & + & - & + & + & & & & & & \\
\hline 16 & 57 & $\mathbf{M}$ & - & - & - & + & & & & & & \\
\hline 17 & 67 & F & + & - & + & + & & & & & & \\
\hline 18 & 46 & $\mathbf{M}$ & + & + & + & + & & & & & & \\
\hline
\end{tabular}

Analyses of the conventional and orthogonal electrocardiograms are presented in Tables 2 and 3, respectively.

Clinical findings Fourteen patients gave a history suggestive of either single or recurrent attacks of myocardial infarction and or angina pectoris. Signs of congestive failure were pre- sent in ro patients on admission, but it was recurrent and resistant in only 3. On physical examination the ventricular aneurysm was suspected in 7 patients usually because of the finding of strong abnormal praecordial pulsations often distinguishable from those of the apical impulse and contrasting with a weak first sound at the cardiac apex. Fluoroscopic

TABLE 2 Analysis of conventional electrocardiogram

\begin{tabular}{|c|c|c|c|c|c|c|c|c|c|c|}
\hline \multirow{2}{*}{$\begin{array}{l}\text { Case } \\
\text { No. }\end{array}$} & \multirow{2}{*}{$\begin{array}{l}\text { QRS } \\
\text { duration } \\
\text { (sec.) }\end{array}$} & \multicolumn{3}{|c|}{ Leads show } & pattern & \multicolumn{2}{|c|}{ or its variants } & \multirow{2}{*}{$\begin{array}{l}\text { Slurring of } \\
-S \text { wave in } \\
\text { lead } V_{4}\end{array}$} & \multirow{2}{*}{$\begin{array}{l}\text { Reversal of } \\
R \text { wave pro- } \\
\text { gression in } \\
\text { praecordial } \\
\text { leads }\end{array}$} & \multirow{2}{*}{$\begin{array}{l}\text { Persistent } S T \\
\text { segment } \\
\text { elevation }\end{array}$} \\
\hline & & $V_{4} / V_{5}$ & $V_{5}$ & V6 & $V_{7}$ & $I$ & $a V L$ & & & \\
\hline
\end{tabular}

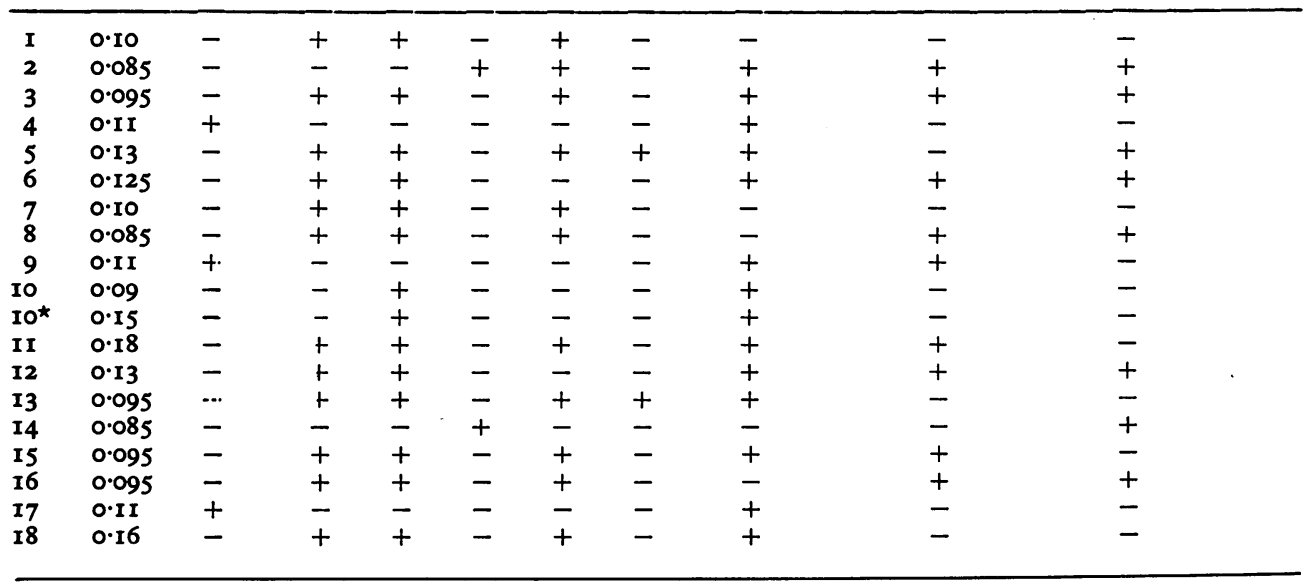

* This case showed intermittent left bundle-branch block. 
TABLE 3 Planar projection (degrees) of 8 instantaneous $Q R S$ vectors (0.0I to 0.08 sec. vectors)

\begin{tabular}{|c|c|c|c|c|c|c|c|c|c|c|c|c|c|c|c|c|c|c|c|c|c|c|c|c|}
\hline \multirow{2}{*}{$\begin{array}{l}\text { Case } \\
\text { No. }\end{array}$} & \multicolumn{8}{|c|}{ Frontal (sec.) } & \multicolumn{8}{|c|}{ Horizontal (sec.) } & \multicolumn{8}{|c|}{ Sagittal (sec.) } \\
\hline & $0.0 I$ & 0.02 & 0.03 & 0.04 & 0.05 & 0.06 & 0.07 & 0.08 & 0.01 & 0.02 & 0.03 & 0.04 & 0.05 & 0.06 & 0.07 & 0.08 & 0.01 & 0.02 & 0.03 & 0.04 & 0.05 & 0.06 & 0.07 & \\
\hline I & 47 & 225 & 36 & 48 & 37 & 55 & 71 & 82 & 59 & 226 & 256 & 280 & 294 & 311 & 330 & 342 & I6 & 253 & 169 & 152 & 139 & 132 & 128 & \\
\hline 2 & 65 & 95 & 135 & 155 & 167 & 191 & 310 & 282 & 65 & 225 & 252 & 26I & 267 & 275 & 273 & 270 & $4 I$ & 44 & 92 & 160 & 173 & 187 & 190 & \\
\hline 3 & 34 & 87 & 133 & 140 & 85 & 220 & 238 & 189 & 38 & 261 & 252 & 258 & 277 & 259 & 264 & 269 & 48 & 118 & 152 & 141 & 128 & 225 & 218 & \\
\hline 4 & 45 & 140 & 154 & 135 & 121 & 30 & 14 & 85 & 5 & 85 & 259 & 250 & 254 & 272 & 307 & 328 & 4 & 6 & 170 & 172 & 164 & I67 & 165 & \\
\hline 5 & 12 & 44 & 93 & 151 & 164 & 138 & 85 & 79 & 34 & 263 & 248 & 252 & 282 & 305 & 314 & 325 & 18 & 54 & 96 & 162 & I74 & I32 & 128 & \\
\hline 6 & 40 & 134 & 128 & 122 & 112 & 24 & 18 & 87 & 12 & 79 & 258 & 248 & 250 & 275 & 305 & 333 & 9 & 12 & 169 & 173 & 161 & I 58 & 165 & \\
\hline 7 & 4 & 32 & 112 & 92 & $4 I$ & 25 & 34 & 162 & 75 & 71 & 260 & 269 & 278 & 314 & 324 & 150 & 12 & 18 & 95 & 164 & 160 & I52 & 92 & \\
\hline 8 & 44 & 218 & 34 & 45 & 33 & 48 & 62 & 73 & 74 & 228 & 259 & 282 & 295 & 305 & 328 & 345 & 4 & 255 & 178 & 155 & 148 & 138 & 135 & \\
\hline 9 & 12 & 34 & 106 & 85 & 34 & 18 & 28 & 161 & 62 & 74 & 248 & 260 & 279 & 310 & 329 & 162 & 28 & 37 & 99 & 159 & 150 & I4I & 92 & \\
\hline I0 & 38 & 79 & 99 & 48 & 42 & 340 & 315 & 318 & 325 & 189 & 225 & 269 & 285 & 298 & 305 & 275 & II 5 & 92 & 150 & 164 & 168 & I54 & 205 & \\
\hline $10^{\star}$ & 34 & 88 & 121 & 98 & 64 & 34 & 28 & 24 & 318 & 235 & 258 & 265 & 292 & 315 & 318 & 305 & 118 & 138 & 158 & 167 & 162 & 159 & 178 & \\
\hline II & 44 & 87 & 132 & 144 & 172 & 175 & 48 & 55 & 82 & 78 & 210 & 242 & 251 & 262 & 277 & 303 & 7 & 12 & 92 & 164 & 172 & 175 & 154 & \\
\hline 12 & 7 & 37 & 92 & 145 & 160 & 134 & 89 & 84 & 314 & 299 & 255 & 249 & 256 & 269 & 278 & 314 & 155 & I5I & 165 & 160 & I44 & I5O & 152 & \\
\hline 13 & 8 & 34 & 108 & 89 & 38 & 22 & 30 & 164 & 64 & 62 & 255 & 261 & 278 & 305 & $33 I$ & 158 & 22 & 34 & 98 & 157 & 152 & I44 & 90 & \\
\hline 14 & 32 & 88 & 130 & 136 & 85 & 223 & 245 & 195 & 44 & 265 & 254 & 261 & 275 & 253 & 264 & 268 & 56 & 122 & I55 & I44 & 126 & 235 & 221 & \\
\hline 15 & 62 & 93 & 129 & ISI & 162 & 190 & 318 & 288 & 40 & 231 & 258 & 265 & 271 & 278 & 273 & 270 & 35 & 42 & 94 & 158 & 166 & 185 & 193 & \\
\hline 16 & 35 & 92 & 189 & 168 & 88 & 24 & 42 & 85 & 62 & 228 & 237 & 239 & 278 & 305 & 274 & 225 & 8 & 40 & I87 & 162 & I58 & 170 & 164 & \\
\hline 17 & $4 I$ & 133 & 149 & 128 & 115 & 42 & 18 & 79 & 21 & 78 & 256 & 248 & 250 & 268 & 3 II & 332 & 7 & II & 165 & 173 & 162 & 160 & 152 & \\
\hline 18 & 38 & 75 & 128 & 145 & 169 & 173 & 42 & 59 & 73 & 58 & 215 & 250 & 255 & $26 I$ & 278 & 308 & 12 & 24 & 95 & 158 & 169 & I74 & 148 & \\
\hline
\end{tabular}

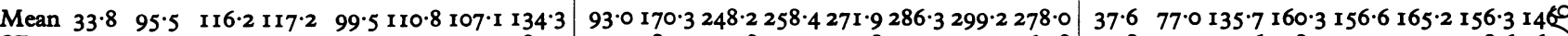

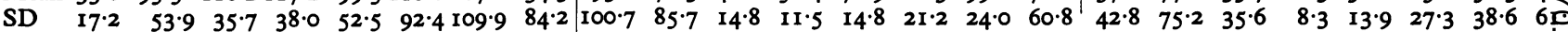

*This case showed intermittent left bundle-branch block.

and radiographic findings were available in 14 patients. The findings confirmed the clinical suspicion of ventricular aneurysm in all patients and suggested it independently

FI G. I ( $A$ ) Chest x-ray, postero-anterior view, showing left pleural effusion obscuring the left cardiac border. (B) One month later, the effusion has been absorbed revealing the characteristic ledge of left ventricular aneurysm.

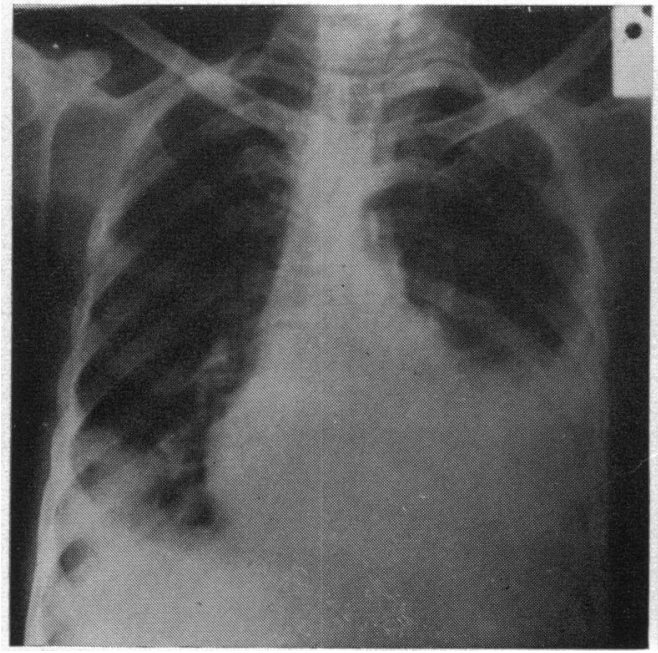

(A) in 3 others. Radiographic examination on admission was sometimes unhelpful due to the presence of left pleural effusion obscuring the left cardiac border. However, in subsequent films and after the absorption of effusion the ventricular aneurysm could be diagnosed (Fig. I).

Post-mortem findings Ventricular aneurysms were present in II out of 12 patients studied. In the last patient there was scarring

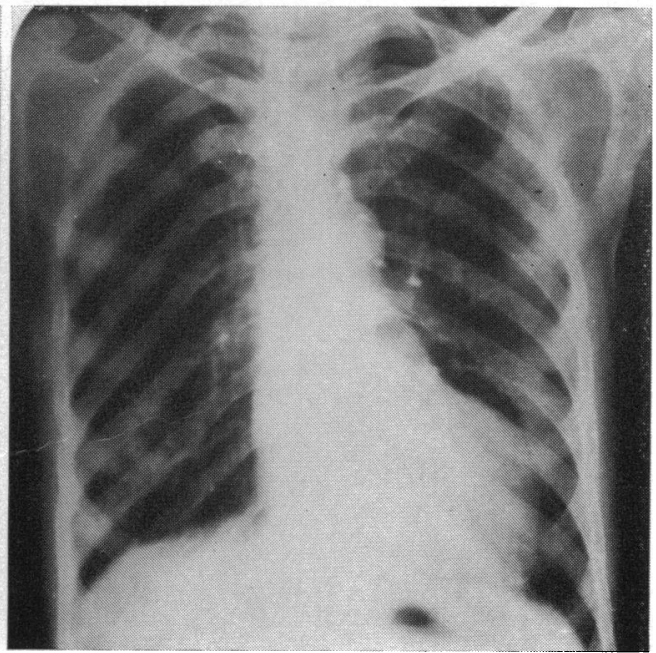

(B) 


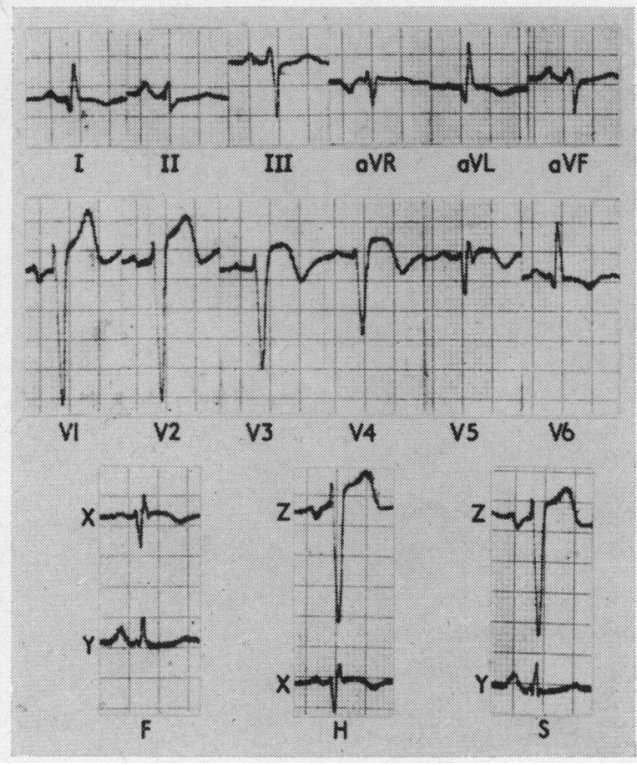

FIG. 2 The standard electrocardiogram shows reversal of $R$ wave progression in praecordial leads and persistent elevation of the $S T$ segment. The slurring on the ascending limb of the $S$ wave in $V_{4}$ has progressed to a small (embryonic) $r^{\prime}$ wave in $V 5$ and a classical rs $R^{\prime}$ in V6. The rs $R^{\prime}$ pattern is also recorded in lead I and the orthogonal $X$ lead. The $Q R S$ duration is $0 \cdot 10$ sec. $X, Z$, and $Y$ are orthogonal scalar leads. $F, H$, and $S$ stand for frontal, horizontal, and sagittal planes.

of the antero-septal and apical regions of the left ventricle, but distension of the left ventricular cavity revealed no specific aneurysmal bulging. The aneurysms always occurred in the site of an extensive confluent area of scarring. This was usually located at the anterior and antero-lateral aspects of the left ventricle. Frequently the scarring involved part of the anterior or lower portions of the interventricular septum. In one case two aneurysms were present on the anterior and posterior aspects of the left ventricular cone. There was usually occlusion or narrowing of the anterior descending branch of the left coronary artery. However, there was no correlation between the affected arteries and the site of the aneurysmal scarring.

Electrocardiographic findings The electrocardiogram showed the characteristic rsR' pattern or its varants in one or more of the left surface leads, usually in $V_{5}$ and V6 but also in leads $\mathrm{I}, \mathrm{aVL}, \mathrm{V}_{7}$, and the praecordial lead between $\mathrm{V}_{4}$ and $\mathrm{V}_{5}$ ( $\mathrm{V}_{4} / \mathrm{V}_{5}$ ), (Fig. 2, 3,
$4 \mathrm{~A}, 5,6,7$, and 8 ). Frequently a clear notching or slurring was seen on the descending limb, nadir, or ascending limb of the $S$ wave in the praecordial leads to the right of the transition zone (usually $\mathrm{V}_{4}$ ). Sometimes this was seen to progress to a small or embryonic $r$ in lead $V_{5}$ and a classical rsR' in lead V6 (Fig. 2 and $3 A$ ). In 2 patients the rsR' pattern was only recorded in V7. In these 2, huge ventricular aneurysms were present. In fact one of them (Fig. 4) was first diagnosed as left pleural effusion and was tapped on that assumption, and pure blood was obtained with the subsequent diagnosis of malignant effusion. Later on and after the electrocardiogram report, careful clinical examination disclosed the presence of myocardial aneurysm.

FIG. 3 ( $A$ ) Lead $V_{5}$ shows an embryonic $r^{\prime}$ wave, while leads $I$ and V6 record the characteristic rs $R^{\prime}$ pattern. The orthogonal $X$ lead shows an $r S r^{\prime}$ pattern, with prominent $S$ wave and an embryonic $r^{\prime}$ wave. The $Q R S$ duration is $0.095 \mathrm{sec}$. (B) Lead V5 shows an $r S R^{\prime}$, while leads $I, V 6$, and the orthogonal $X$ lead record an rs $R^{\prime}$ pattern with diminutive s wave and a prominent $R^{\prime}$ wave. The $Q R S$ duration is $0 \cdot 10$ sec. $Z$ and $X$ are orthogonal scalar leads. $H$ stands for the horizontal plane.

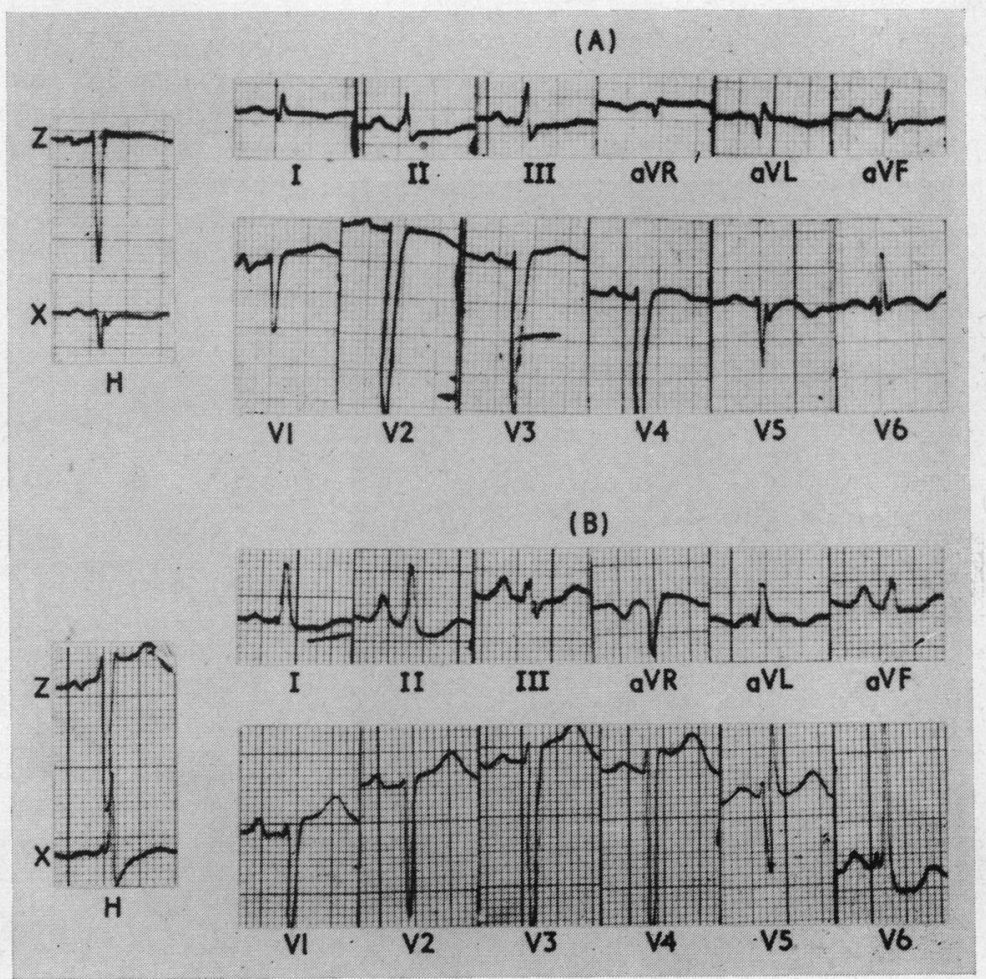




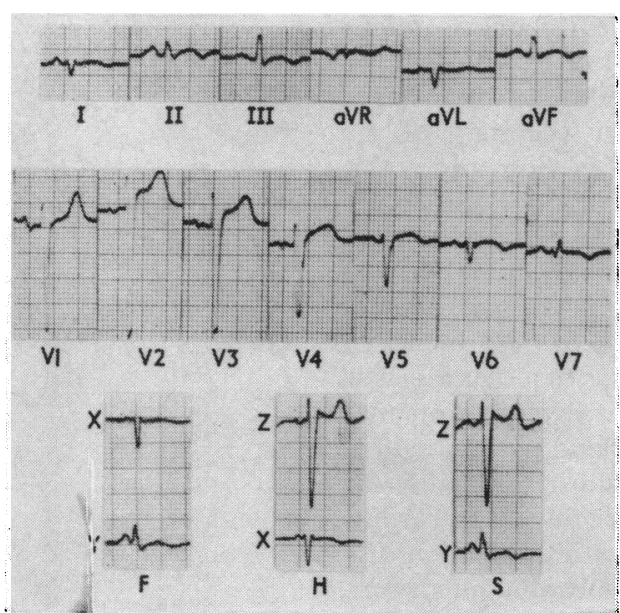

(A)

FIG. 4 ( $A)$ The standard electrocardiogram shows reversal of $R$ wave progression in praecordial leads and persistent elevation of $S T$ segment. The rs $R^{\prime}$ pattern is not recorded up to $V 7$. The orthogonal $X$ lead shows an $r S r^{\prime}$ pattern with diminutive $r^{\prime}$. The $Q R S$ duration is 0.085 sec. $X, Y$, and $Z$ are orthogonal scalar leads. $F, H$, and $S$ stand for frontal, horizontal, and sagittal planes.

(B) Chest $\mathrm{x}$-ray, postero-anterior view, of the same patient showing a huge myocardial aneurysm. The $\mathrm{x}$-ray was first interpreted as a left pleural effusion.

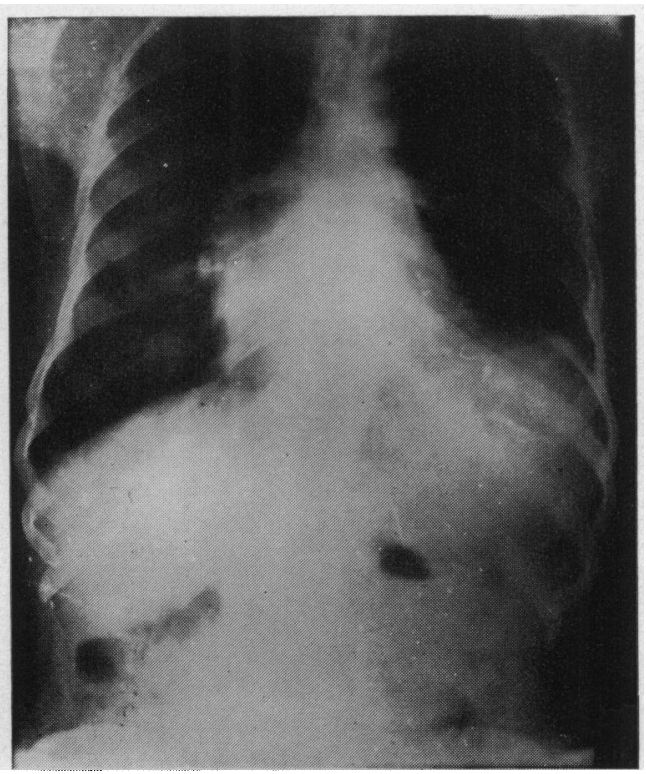

(B)

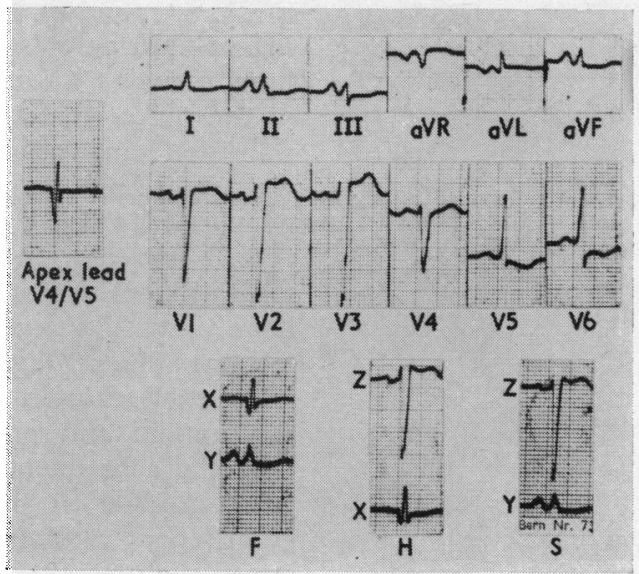

FIG. 5 The standard electrocardiogram shows a pattern consistent with incomplete left bundle-branch block. The QRS duration is 0.11 sec. There is a sudden transition from an $r S$ pattern with slurred $S$ wave in lead $V_{4}$ to an $R$ pattern in lead V5. The praecordial lead between $V_{4}$ and $V_{5}\left(V_{4} / V_{5}\right)$ which is overlying the apex records an $r S R^{\prime}$ pattern which is also recorded in the orthogonal $X$ lead.

FIG. 6 The standard electrocardiogram showed reversal of the $R$ wave progressive in the praecordial leads. The conspicuous notching of the $S$ wave in lead $V_{4}$ has progressed to an rsR' pattern in leads $V_{5}$ and V6. The pattern is also recorded in lead I and the orthogonal scalar $X$ lead. The $Q R S$ duration is 0.18 sec. $X, Z$, and $Y$ are orthogonal scalar leads. $F, H$, and $S$ stand for frontal, horizontal, and sagittal planes.

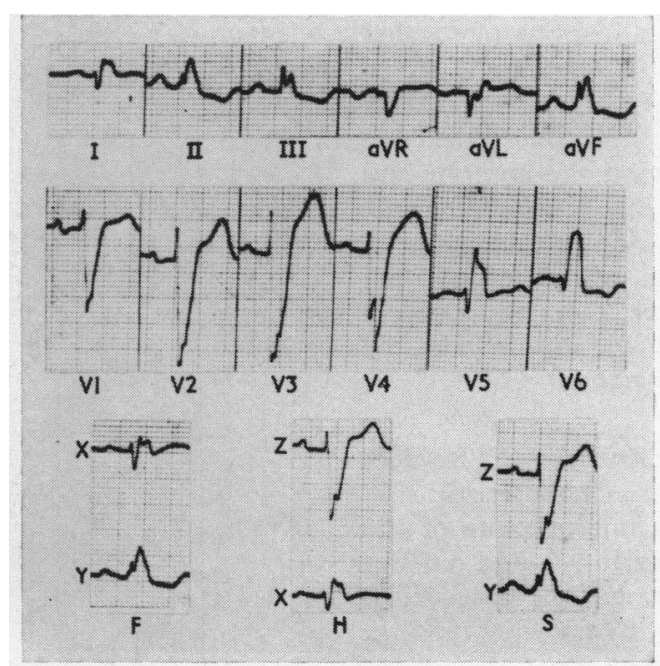




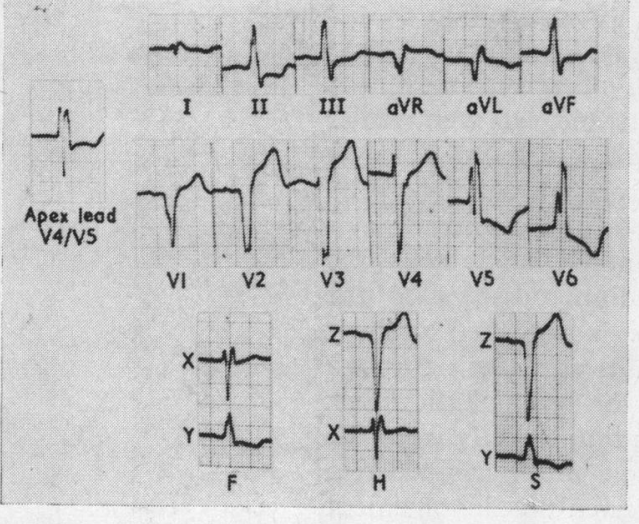

FIG. 7 The standard electrocardiogram shows slurring of the ascending limb of the $S$ wave in lead $V_{4}$ which progresses to a deeply notched $R$ wave in lead $V_{5}$. A lead overlying the apex between $V_{4}$ and $V_{5}$ $\left(V_{4} / V_{5}\right)$ shows the characteristic $r S R^{\prime}$ pattern which is also recorded in the orthogonal $X$ lead. The $Q R S$ duration is $0.13 \mathrm{sec}$. $X, Z$, and $Y$ are orthogonal scalar leads. $F, H$, and $S$ stand for frontal, horizontal, and sagittal planes.

FIG. 8 The electrocardiogram shows an intermittent left bundle-branch block in the presence of atrial fibrillation. The first complex represents normal conduction while the second complex shows left bundle-branch block. Leads $V_{2}$ and $V_{4}$ show slurring of the $S$ waves during both normal conduction and left bundle-branch block, while lead V6 shows the characteristic rs $R^{\prime}$ pattern during both types of conduction.

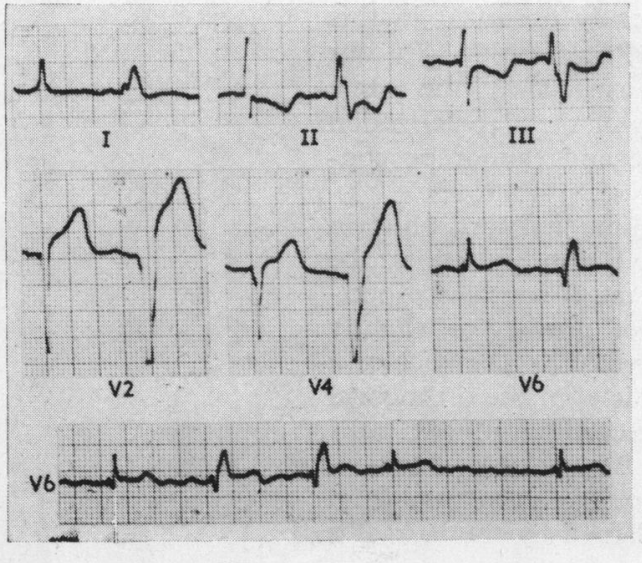

In 3 patients the conventional praecordial leads showed a sudden transition from an $\mathrm{rS}$ pattern with slurred $S$ wave in $V_{4}$ to an $R$ pattern (sometimes notched) in $\mathrm{V}_{5}$, but the praecordial lead in between $\left(\mathrm{V}_{4} / \mathrm{V}_{5}\right)$ which overlaid the apical impulse in these patients showed a characteristic rsR $^{\prime}$ pattern (Fig. 5 and 7). Two of these patients came to necropsy, when the aneurysm involving the cardiac apex was clearly seen.

The QRS duration varied widely from 0.085 to $0.18 \mathrm{sec}$. In 12 patients, the QRS duration was less than 0.12 sec. (Fig. 2, 3, 4 , and 5). Reversal of normal $R$ wave progression in the praecordial leads was found in 9 patients and persistent elevation of the ST segment in one or more of the praecordial leads in 8 patients.

The orthogonal $\mathrm{X}$ lead always showed the characteristic $\mathrm{rsR}^{\prime}$ pattern or its variants. Analysis of the spatial projection of the instantaneous $Q R S$ vectors showed a consistent initial direction to the left and frequently anteriorly and inferiorly. This was soon followed within 0.02 to 0.03 sec. by a shift in the direction to the right and posteriorly that persisted from 0.03 to $0.06 \mathrm{sec}$. after the beginning of the depolarization wave before it turned again to the left and posteriorly. The duration of the rightward shift varied slightly from one case to another, while the duration and the extent of the terminal leftward deflexion showed considerable variation.

\section{Discussion}

The rsR' pattern in V6 was mentioned by Chapman and Pearce (1957) in connexion with left bundle-branch block. They considered the pattern diagnostic of antero-septal infarction, and referred to similar findings by Rosenbaum et al. (1944) during experimental myocardial infarction with left bundle-branch block in dogs. Burch, Horan, and Cronvich (1959) and Burch, Ziskund, and Cronvich (1958) described the pattern with essentially prolonged QRS complex in 13 out of 24 cases of ventricular aneurysms, and in 4 other cases with extensive scarring of the left ventricle, and speculated on its genesis. Later on, the $r^{\prime} R^{\prime}$ pattern was only mentioned in relation to left bundle-branch block as evidence suggestive of myocardial infarction. However, in a clinico-pathological correlation (Scott, I965), the diagnostic specificity of the pattern was doubted. In a recent vectorcardiographic study of left bundle-branch block with myocardial infarction, Doucet, Walsh, and Massie (1966) described a pattern for the 
depolarization wave very similar to the one found in this work, but they did not analyse the electrocardiogram or carry out a necropsy study.

Analysis of our data discloses two important observations to be considered in any attempt to evaluate the electrocardiographic pattern. First, the consistent finding in necropsies of an extensive confluent area of scarring affecting the anterior and anterolateral portions of the left ventricular cone, with frequent involvement of the interventricular septum, suggests a cause and effect relation for the characteristic electrocardiographic pattern. Secondly, the pattern was frequently found in association with a normal or slightly prolonged QRS duration. However, the type of disturbance of the initial part of the depolarization wave was remarkably similar, irrespective of the total QRS duration.

The initial leftward direction of the depolarization wave speaks of right to left activation of the interventricular septum, which can be caused either by involvement of the left bundle or infarction of the left septal myocardium. It seems that either or both mechanisms are possible. In the presence of normal or slightly prolonged QRS duration, the involvement of the left septal myocardium is more feasible, while in the presence of prolonged QRS duration involvement of the left bundle with delay in the activation of the left ventricle is the likely explanation. The frequent affection of the anterior or lower portions of the interventricular septum in the cases studied at necropsy is remarkable in this connexion.

The early rightward shift of the instantaneous QRS vectors seems to be related to the extensive area of confluent scarring which acts as a sort of electrical barrier in the progress of the depolarization wave in the left ventricular myocardium. The similar timing and duration of this shift in the presence of both normal QRS duration and left bundlebranch block can only be explained by assuming the involvement in both conditions of an area of the left ventricular wall that begins to be activated relatively early (within 0.02 to $0.03 \mathrm{sec}$. from the beginning of the depolarization wave). During this period electrical activation of uninvolved parts of the myocardium (either the right ventricular wall or upper part of the septum or both) causes the shift of the instantaneous $Q R S$ vectors to the right and posteriorly. This seems possible in cases with normal or slightly prolonged QRS duration, where activation of the left ventricular myocardium usually starts early. On the other hand, cases with left bundle-branch block with a delay in the activation of the left ventricular wall may be difficult to explain. The mechanism of activation of the interventricular septum and left ventricular wall in the presence of left bundle-branch block is still controversial (Scott, 1962). However, there is good experimental evidence that after left bundle-branch block, the left ventricular epicardium adjacent to the interventricular groove is activated without delay either by impulses spreading through Purkinje fibres below the level of the block or from impulses spreading directly from the right ventricle in muscle fibres (Seidenstein et al., 1962). It is suggested that involvement of these areas of the left ventricle, which are early activated in the presence of left bundlebranch block, can explain the characteristic cardiographic pattern both in the presence of normal and prolonged QRS duration. This hypothesis was substantiated in one of our patients with the $\mathrm{rsR}^{\prime}$ pattern in V6, who showed an intermittent left bundle-branch block in the presence of atrial fibrillation (Fig. 8). With the development of left bundlebranch block an rsR' pattern in V6 changed to an $\mathrm{rSR}^{\prime}$, with a more prominent $S$ wave and a broad terminal $R$ wave. The primary effect of left bundle-branch block was on the late part of the depolarization process (the terminal $R$ wave), with slight affection of the basic pattern of the initial depolarization (Table 3, Case ro). The findings in this case could be explained if we assumed that the early rightward shift of the depolarization wave was due to involvement of parts of the left ventricular wall which were early activated both with normal conduction and in the presence of left bundle-branch block.

The presence of notching or slurring of the $S$ wave in praecordial leads to the right of the transition zone, which was sometimes related to myocardial infarction in the presence of left bundle-branch block (Scott, 1965), was also frequently observed in this study with normal QRS duration. In our cases the slurring must reflect the same changes in the pathway of the depolarization wave mentioned above and cannot be considered separately.

The degree of terminal leftward shift in the depolarization wave can sometimes be correlated with the extent of scarring, especially in the presence of normal or slightly prolonged QRS duration. The presence of a diminutive or embryonic $r^{\prime}$ in the orthogonal $X$ lead and/or the recording of the rsR' $^{\prime}$ pattern only in leads to the left of V6 in association with huge ventricular aneurysm (Fig. $3 A$ and 4) can be explained by the lack of a 
significant amount of viable myocardium in the left ventricular cone in these cases. On the other hand, the inscription of an rSR' pattern in the apex lead (in presence of an apical aneurysm) raises the question of the effect of localized potentials on the electrocardiogram with the aneurysm exercising a window effect. However, the consistent recording in these cases of the $r s R^{\prime}$ pattern in the orthogonal $\mathrm{X}$ lead shows that the aneurysmal scarring is affecting the whole pathway of the depolarization process. This situation offers a proof of the validity of the vectorial concept as a good working hypothesis, not ignoring at the same time the minor contributions from non-dipolar sources, especially in the praecordial leads (Pipberger and Pipberger, 1964).

In conclusion, the presence of an $\mathrm{rsR}^{\prime}$ pattern or one of its variants in left surface leads and particularly in the orthogonal $\mathrm{X}$ lead in the presence of normal or prolonged QRS duration can be highly suggestive of an extensive confluent scarring of the left ventricular cone. It is to be remembered that extensive confluent scarring is the forerunner of ventricular aneurysm which can be safely suggested in these cases. Though no systematic study of the over-all incidence of this pattern in ventricular aneurysms was attempted, the pattern seems to be not uncommon. The recognition of this pattern may be of diagnostic value in certain instances. The citing of the following case is illustrative.

A 43-year-old man was admitted in congestive heart failure. The patient gave a history of 6 months' duration starting with congestive lung symptoms in the wake of an influenzal attack but soon followed evidence of congestive failure. There was no history suggestive of coronary heart disease. Physical examination revealed an enlarged heart with a left ventricular type of impulse and a protodiastolic gallop over the apex. $X$-ray showed cardiac enlargement with the left ventricular border obscured by left pleural effusion. The standard electrocardiogram (Fig. 5) showed a picture of incomplete left bundle-branch pattern. The patient was conventionally diagnosed as having primary myocardial disease. However, the orthogonal electrocardiogram showed the characteristic $r s R^{\prime}$ pattern in the $X$ lead. This stimulated the redrawing of the praecordial leads, and the lead overlying the apex showed an $\mathrm{rsR}^{\prime}$ pattern. The possibility of a ventricular aneurysm secondary to a silent myocardial infarction was suggested. The patient response to the anti-failure regimen was poor, and 22 days after admission the patient suddenly perished. Necropsy revealed an extensive scarring involving the left ventricular apex with an aneurysmal bulge 8 by $9 \mathrm{~cm}$. in diameter.

\section{References}

Burch, G. E., Horan, L. G., and Cronvich, J. A. (1959). An electrocardiographic and spatial vectorcardiographic pattern associated with diffuse myocardial damage and ventricular aneurysm. American Heart fournal, 57, 762.

$\longrightarrow$, Ziskind, J., and Cronvich, J. A. (1958). A correlative study of post-mortem, electrocardiographic, and spatial vectorcardiographic data in myocardial infarction. Circulation, 18, 325.

Caskey, T. D., and Estes, E. H., Jr. (1964). Deviation of the S-T segment. A review. American fournal of Medicine, 36, 424.

Chapman, M. G., and Pearce, M. L. (1957). Electrocardiographic diagnosis of myocardial infarction in the presence of left bundle-branch block. Circulation, 16, 558.

Doucet, P., Walsh, T. J., and Massie, E. (1966). A vectorcardiographic and electrocardiographic study of left bundle-branch block with myocardial infarction. American fournal of Cardiology, 17, 171 .

Dubnow, M. H., Burchell, H. B., and Titus, J. L. (I965). Postinfarction ventricular aneurysm. A clinico-morphologic and electrocardiographic study of 80 cases. American Heart fournal, 70, 753.

Edwards, J. E. (1961). An Atlas of Acquired Diseases of the Heart and Great Vessels, Vol. II. Coronary Arterial Disease, Systemic Hypertension, Myocardiopathies, the Heart in Systemic Diseases and Cor Pulmonale, Acute and Chronic. Saunders, Philadelphia and London.

El-Sherif, N., El-Ramli, Z. M., Sorour, A. H., and Sallam, F. A. (I966). The orthogonal electrocardiogram. Bulletin of the Egyptian Society of Cardiology, 11, 63.

Frank, E. (1956). An accurate, clinically practical system for spatial vectorcardiography. Circulation, 13, 736.

Goldberger, E., and Schwartz, S. P. (1948). ECG patterns of ventricular aneurysm. American fournal of Medicine, 4, 243.

Langner, P. H., Jr., Okada, R. H., Moore, S. R., and Fies, H. L. (1958). Comparison of four orthogonal systems of vectorcardiography. Circulation, 17, 46.

Moyer, J. B., and Hiller, G. I. (I95I). Cardiac aneurysm: clinical and ECG analysis. American Heart fournal, 41, 340.

Pipberger, H. V., and Pipberger, H. A. (1964). Display and analysis of electrocardiographic data. American fournal of Cardiology, 14, 307.

Rosenbaum, F. F., Erlanger, H., Cotrim, N., Johnston, F. D., and Wilson, F. N. (1944). The effects of anterior infarction complicated by bundlebranch block upon the form of the QRS complex of the canine electrocardiogram. American Heart fournal, 27, 783 .

Samson, W. E., and Scher, A. M. (I960). Mechanism of S-T segment alteration during acute myocardial injury. Circulation Research, 8, 780 .

Schlichter, J., Hellerstein, H. K., and Katz, L. N. (1954). Aneurysms of the heart: a correlative study of one hundred and two proved cases. Medicine, 33, 43.

Schwedel, J. B. (1946). Ventricular aneurysm. In Clinical Roentgenology of the Heart, p. 87. Hoeber, New York.

$\longrightarrow$, and Gross, H. (1939). Ventricular aneurysm. Roentgenographic and post-mortem surveys. American fournal of Roentgenology, Radium Therapy, and Nuclear Medicine, 41, 32.

Scott, R. C. (1962). Current concepts of ventricular activation in the normal heart, in left bundle-branch 
block, and in left bundle-branch block with myocardial infarction. American Heart fournal, 64, 696.

(1965). Left bundle-branch block: a clinical assessment. Part II. American Heart fournal, 70, 691.
Seidenstein, M., Hoffman, B. F., Stuckey, J. H., Venerose, R. S., and Michaels, L. (1962). Activation of the epicardial surface of the left ventricle following left ventriculotomy and left bundlebranch block. American fournal of Cardiology, 10, 